\title{
PRISCIAMVS MINOR: TEORÍA GRAMATICAL PER FIGVRAM Y TÉCNICA COMPOSITIVA (II) ${ }^{1}$
}

\author{
MARCOS A. GuTIÉRREZ \\ Universidad del País Vasco/EHU \\ marcoantonio.gutierrez@ehu.eus
}

Recibido: $15 / 11 / 18$

Aceptado: 14/05/19

En el presente artículo damos cuenta pormenorizada de los ejemplos per figuram obtenidos a través de un novedoso método de trabajo plasmado en DECOTGREL (Pmin) (2013). De esta forma hemos podido sistematizar todos los 'usos especiales' documentados en el así llamado Priscianus minor. De esta manera hemos podido encontrar consideraciones que van más allá de lo meramente normativo y que tienen un gran interés tanto para el conocimiento de la lengua en cuestión como para el análisis de la evolución de los conceptos gramaticales y de las teorías lingüísticas desde la Antigüedad hasta la Modernidad.

Diccionario electrónico / DECOTGREL / Figura / Latín / Lexicografía técnica

PRISCIANVS MINOR: GRAMMATICAL THEORY AND TECHNIQUE OF COMPOSITION

In this article we give full details of the per figuram examples obtained through a novel method used in the elaboration of the DECOTGREL (Pmin) (2013). We have collected and systematize all 'special uses' documented in the so called Priscianus minor. With this method we have been able to find in these ancient treatises a lot of times suggestive remarks about facts which go further than a simple normative point of view and which have a great interest for a better knowledge of the language (Greek or Latin, for instance) as much as for a more detaliled study of the evolution experienced by grammatical concepts and linguistic theories from the Antiquity to the Modernity.

Electronic Dictionary / DECOTGREL / Figure / Latin / Technical Lexicography 


\section{El tiempo-modo per figuram}

Como es sabido, los accidentes de tiempo y modo son los que propiamente caracterizan al verbo. Por tal motivo no debe extrañarnos que también los ejemplos per figuram relativos a ambos que hemos documentado en el Priscianus minor sean también numerosos. En efecto, éstos ascienden a un total de 80 , lo que supone un porcentaje relativo del $26,8 \%$.

Los asuntos básicos a los que remiten tales ejemplos son los siguientes: usos de un tiempo por otro, bien sean relativos al presente ([61]), al pretérito ([62]), o al futuro ([63]); posibilidad de utilizar una perífrasis en lugar de la forma sintética ([64]); usos de un modo por otro ([65]), relativos al indicativo ([66]), al subjuntivo o/y optativo ([67-69]), o al infinitivo ([70-71]):

[61] et sciendum, quod tam poetae quam prosarum scriptores frequenter praesentibus utuntur tam pro praeteritis quam pro futuris, contra autem raro (K: 17, 191)

Hay que saber que tanto los poetas como los prosistas con frecuencia utilizan presentes en lugar de pasados o futuros, pero al revés no es usual.

[62] in huiuscemodi sensu Romani solent non solum praeteritis imperfectis, sed etiam perfectis uti pro praesentibus vel futuris tam subiunctivis quam indicativis (K: 18, 335)

Con un significado de este tipo, los romanos suelen no sólo utilizar los pretéritos imperfectos, sino también los perfectos, en lugar de los presentes, o futuros, tanto subjuntivos como indicativos.

[63] sic enim solent plerique ponere 'inquam', quod est futuri, loco praeteriti vel praesentis accipientes (K: 17, 191)

Del mismo modo, muchos suelen utilizar inquam, que es de futuro, con el valor de pasado o de presente.

[64] Horatius in I carminum: //

Quis Martem tunica tectum adamantina

Digne scripserit?

pro 'scribere potuerit' (K: 18, 251-252)

Horacio en I de Odas,

Quis Martem tunica tectum adamantina

Digne scripserit?

Con el valor de "podrá escribir". 
[65] Inveniuntur tamen auctores et indicativis et optativis et subiunctivis usi pro imperativis, quomodo supra ostendimus (K: 18, 238)

Con todo, encontramos también escritores que utilizan indicativos, optativos y subjuntivos en lugar de imperativos.

[66] Virgilius in VIII:

aut si qua id fortuna vetabit,

Absenti ferat inferias,

vetabit pro 'vetet' dixit metri causa (K: 18, 246-247)

Virgilio en el VIII:

aut si qua id fortuna vetabit,

Absenti ferat inferias,

que escribió vetabit en lugar de vetet por motivos métricos.

[67] et Graeci quidem, maxime Attici etiam sine deprecatione solent hoc modo uti pro indicativo, nos vero minime, quamvis similes sint eius voces subiunctivi vocibus, quibus frequentissime pro indicativis utuntur auctores nostri (K: 18,239)

En griego, y sobre todo en ático, incluso sin que se trate de un ruego, suelen utilizar este modo en lugar del indicativo. Nosotros, en cambio, no, aunque las formas del optativo sean iguales a las del subjuntivo, que en latín es usado con mucha frecuencia por los autores en lugar de indicativo.

[68] in hoc sensu frequenter invenimus pro infinito verbo subiunctivum poni, ut 'iubeo facias' (K: 18, 227)

en este sentido, con frecuencia, en lugar de un infinitivo aparece el subjuntivo del verbo, como en iubeo facias ("te mando que hagas").

[69] potest enim per connumerationem aliquis sese illis, quibus imperat, adiungere, ut dux suos milites iubens committere proelium aptissime dicit 'pugnemus, confligamus' (K: 18,237)

Así, por agrupación, alguien puede unirse a aquellos a los que les da una orden. Por ejemplo, un general, al dirigirse a sus soldados en un combate, puede decir de manera muy apropiada: pugnemus, confligamus ("luchemos, ataquemos").

[70] Ab infinito incipit exponere verbi ordinationem Apollonius, ostendens, hoc verbum generale esse et pro omni posse accipi modo verborum (K: 18, 224) 
Apolonio comienza a exponer la ordenación del verbo a partir del infinitivo, indicando que es el verbo general y que puede sustituir a un verbo en cualquier modo.

[71] nec mirum infinita, quae cognationem habent ad omnes modos, pro quibusdam eorum poni, et maxime pro defectivis, cum sint et ipsa defectiva (K: 18, 228)

Ciertamente no es raro que, si los infinitivos tienen puntos de contacto con todos los modos, aparezcan en su lugar, y sobre todo con verbos defectivos, puesto que también ellos mismos son defectivos.

\section{La persona per figuram}

En lo que hace a los usos de la persona per figuram, éstos suman un total de 22, cifra que supone un porcentaje relativo del $7,3 \%$, muy inferior, como era de esperar, al de los accidentes ya vistos, el caso y el tiempo-modo.

Un buen número de los ejemplos que nos ocupan hacen referencia a la conceptio personarum ([71-73]); el resto son consideraciones sobre algunas particularidades del accidente en cuestión, como las que se comentan en [74]:

[71] itaque praecipuum habuerunt accidens demonstrationem, quae profecta per coniunctionem primae et secundae personae pervenit etiam ad tertiam (K: 17, 150)

Por eso, se ha considerado la deixis como su cualidad esencial, que, a partir de afectar a la primera y a la segunda persona, afectó también a la tercera.

[72] et in prima quidem persona licet per conceptionem secundam assumere et tertiam, ut 'ego et tu legimus', 'ego et ille scribimus'; a secunda vero prima concipi non potest, tertia vero potest, ut 'tu et ille vosmet ipsos laeditis' (K: $17,178)$

También en la primera persona se puede entender comprendida la segunda y la tercera. Así, en ego et tu legimus, ego et ille scribimus ("yo y tú leemos, yo y él escribimos"). Por su pate, la segunda no puede comprender la primera, pero sí a la tercera: tu et ille vosmet ipsos laeditis ("tú y él os dañáis a vosotros mismos").

[73] similiter quando diversae uno sociantur verbo personae, necesse est nominativos coniungi: 'ego et tu et ille docemus' (K: 17, 203-204)

De forma similar, cuando se unen personas distintas con un solo verbo, es necesario que lo que se unan sean nominativos: ego et tu et ille docemus ("yo, tú y él enseñamos"). 
[74] nec prima tamen primam nec secunda secundam potest possidere, nisi, sicut ostendimus, figurate dicat aliquis 'ego sum meus dominus et servus, tu es tuus et doctor et discipulus', ut Persius:

Vindicta postquam meus a praetore recessi (K: 17, 205)

Tampoco puede la primera poseer a la primera, como hemos dicho, ni la segunda a la segunda, a no ser que, con una expresión figurada, alguien dijera: ego sum meus dominus et servus, tu es tuus et doctor et discipulus ("yo soy mi señor y mi esclavo; tú eres tu profesor y discípulo"). Esto es lo que encontramos en Persio:

Vindicta postquam meus a praetore recessi.

\section{El género y el número per figuram}

El género y el número son los dos accidentes que menos atención reciben en el Priscianus minor. Del primero sólo documentamos 7 ejemplos per figuram (2,3\%), y del segundo $12(4,0 \%)$. Estos bajos porcentajes resultan algo engañosos si se comparan con la importancia de dichos accidentes. Tal vez la explicación de ello sea que en el Priscianus minor, como es bien sabido, predominan las consideraciones sintácticas sobre las morfológicas propiamente dichas.

En lo relativo a los usos per figuram, éstos hacen referencia al uso de un género por otro debido a una concertación ad sensum ([75]), o bien al hecho de que un sustantivo pueda tener más de un género ([76]):

[75] et per diversa genera:

Qualis eram, cum primam aciem Praeneste sub ipsa,

Virgilius in VIII. quamvis enim Praeneste neutrum sit, sed quia 'urbs' intellegitur, ad id quod intellegitur quam ad vocem nominis reddidit dicens sub ipsa (K: 17,201)

O con distintos géneros:

Qualis eram, cum primam aciem Praeneste sub ipsa, como encontramos en el libro VIII de Virgilio, donde, aunque "Preneste" es neutro, como por el sentido indica una ciudad, la referencia a ella es mediante ipsa.

[76] quomodo apud nos 'hic' et 'haec stirps' et 'finis, silex' et multa alia (K: $18,361)$

De manera similar, también nosotros decimos hic y haec stirps ("este o esta descendiente"), e igualmente con finis, silex ("fin", "pedernal") y otros muchos. 
Los ejemplos per figuram relativos al número se refieren básicamente al uso del singular por plural ([77-78]), o bien a usos particulares ([79]):

[77] Eí $\pi \varepsilon ́$ uo dicunt Attici etiam ad multos. huic simile Terentius in eunucho: aperite aliquis actutum (K: 18, 304)

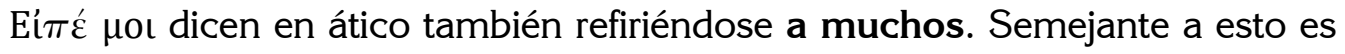
lo que encontramos en El Eunuco de Terencio:

aperite aliquis actutum.

[78] diversi quoque numeri hoc modo figurati reperiuntur, ut Virgilius in I Aeneidis:

Pars in frusta secant veribusque trementia figunt.

plurale singulari non ad dictionem, sed ad sensum retulit, quia pars Troianorum multi intelleguntur (K: 17, 201)

También se unen mediante una figura de este tipo números diferentes, como vemos en el libro I de Eneida de Virgilio:

Pars in frusta secant veribusque trementia figunt, donde un plural concierta no con un término también plural por la forma, sino por el sentido, porque pars se refiere a varios troyanos.

[79] Et sciendum, quod, quia primitivum eius tam singulare quam plurale est, licet in possessivo et unum et plures possessores eius intellegere pro significatione genetivi ad possessorem pertinentis, et 'suus illius' et 'suus illorum' (K: 17, 171)

Hay que saber también que, puesto que su pronombre primario correspondiente es tanto singular como plural, en el posesivo también se pueden entender uno o varios poseedores, equivalentes al significado del genitivo que acompaña al posesor: suus illius o suus illorum ("suyo, de él o de ellos").

\section{Semántica per figuram}

El número de ejemplos per figuram en el Priscianus minor que puede de una u otra manera, en mayor o en menor grado, ser incluido dentro del campo de la semántica resulta, en principio, sorprendente. Su número (52, lo que supone un porcentaje global del 6,6\%), es, en efecto, superior al referido a las preposiciones (46) y solo un poco inferior al de los adverbios (55). Sin embargo, este hecho ha de ser puesto en relación con el valor metodológico y uso práctico que Prisciano en sus Institutiones grammaticae hace de la significatio, a la que el gramático de Constantinopla considera como una contraparte de la morfonsintaxis, como puede deducirse de la cita que sigue ${ }^{2}$ : 
nulla enim alia re discernuntur a se tam partes orationis quam accidentia eis nisi significatione [...]; 'poetae, Musae, diei, rei' et genetivi sunt et dativi. significatione igitur discernuntur a se, quae attentissime est in omnibus inspicienda (K: 13, 4).

por ninguna otra cosa se diferencian entre sí tanto las partes de la oración cuanto sus accidentes como por la significación [...]; poetae, Musae, diei, rei son genitivos y también dativos. Por consiguiente, se diferencian entre sí por su significación, que ha de ser considerada en todos con especial atención.

A tenor de las palabras que preceden, la significatio es el instrumento por excelencia que permite deslindar coincidencias o/y ambigüedades en el plano de las clases de palabras y en el de los accidentes. Por lo tanto, debemos pensar que Prisciano hace un uso habitual de ella ${ }^{3}$.

Un asunto que nos parece particularmente relevante en relación con el papel que se concede a la significatio es el hecho de que a través de ella Prisciano pone en relación dialéctica el nivel morfosintáctico / formal con el semántico / contextual de suerte que al menos virtualmente genera un tercer nivel, de tipo 'ideacional', antesala y frontera de lo que hoy llamaríamos 'pragmática'. Esta intención implícita de convertir la 'necesidad interpretativa' en 'virtud discursiva' parece ser la que se adivina en la acotación final de la cita anterior: significatione igitur discernuntur a se, quae attentissime est in omnibus inspicienda.

Pasamos ahora a dar cuenta de los diversos tipos en que hemos clasificado los usos de este apartado. En el nivel más básico están aquellos contextos que tienen como referencia una sola palabra; su número asciende a 15 (lo que supone un porcentaje relativo de un 28,8\%). En [81-83] ejemplificamos los usos de mayor interés. En segundo lugar, están aquellos contextos en los que la referencia es un sintagma o una oración; son 36 (69,2\% de porcentaje relativo). De los casos más significativos damos cuenta en [84-87]. Por último, hemos documentado 1 (1,9\%) caso relativo a derivación o/y falsa etimología, de ello queda constancia en [88].

Queremos, por último, reseñar que el 69,2\% de usos per figuram que tienen como referente un grupo de palabras (bien sea un sintagma, bien una oración) vienen a confirmar la idea que hemos expresado un poco más arriba en el sentido de que Prisciano es consciente de que el nivel morfosintáctico y el semántico se entrecruzan e interactúan. Más aún, incluso en algunos ejemplos en los que el elemento de referencia es una sola palabra podemos ver cómo la 'sombra' de lo semántico se alarga hasta invadir los que nosotros calificaríamos como pragmático 4 . En [80] queda patente cuanto acabamos de decir.

[80] est enim quando amplioris causa significationis adduntur ea, quae possunt, etsi non addantur, intellegi, ut 'legis?' 'etiam lego' (K: 17, 156) 
$Y$ es que hay ocasiones en que, para reforzar el significado, se expresan elementos que, aunque se elidan, se comprenden. Así, legis? (“clees?”).etiam lego ("sí, leo").

[81] Virgilius Aeneidis I:

Tristior et lacrimis oculos suffusa nitentes, tristior pro ‘subtristis'. (K: 17, 192)

Y Virgilio en el libro I de Eneida:

Tristior et lacrimis oculos suffusa nitentes, donde encontramos tristior por subtristis.

[82] 'assertio' tam a servitute in libertatem quam a libertate in servitium trahi significat, quod apud Livium in multis legimus locis (K: 18, 365)

assertio ("aserción") significa tanto pasar de la servidumbre a la libertad como de la libertad a la servidumbre, como leemos en muchos lugares de Livio.

[83] Lucanus in X:

Sideribus quaecumque fugam moderantur Olympi, moderantur pro 'regunt' $(\mathrm{K}: 18,273)$

Lucano en el X:

Sideribus quaecumque fugam moderantur Olympi, moderantur equivale a regunt.

[84] Iuvenalis in I:

Nec quereris patri nec terram cuspide quassas?

intellegitur enim 'Romanos quereris apud patrem' (K: 18, 275-276)

Juvenal en I:

Nec quereris patri nec terram cuspide quassas?

Donde se sobreentiende Romanos quereris apud patrem.

[85] et Graeci quidem in huiuscemodi sensu genetivo tantum utuntur, Latini vero etiam ablativo frequentius, ut 'magna virtute vir' pro 'magnam virtutem habens'; 'egregia pulchritudine mulier' pro 'egregiam pulchritudinem habens' (K: 18, 214)

$\mathrm{Si}$, en griego, para expresar un significado de este tipo, utilizan sólo el genitivo, en cambio, en latín es más frecuente el ablativo, como en magna virtute vir ("hombre de gran valor") por magnam virtutem habens ("que tiene gran valor"); egregia pulchritudine mulier ("mujer de excelsa belleza”) por egregiam pulchritudinem habens ("que posee una belleza excelsa"). 
[86] 'ardeo uxorem', quando pro 'amo' accipitur. Virgilius in bucolico:

Formosum pastor Corydon ardebat Alexin (K: 18, 267)

ardeo uxorem ("ardo por mi esposa"), cuando significa amo ("amo"). Virgilio en Bucólicas:

Formosum pastor Corydon ardebat Alexin.

[87] et nota, quod tam ad reverentiam honestae personae quam ad pudorem turpis refertur supra dicti constructio verbi, ut 'pudet me patris' pro 'erubesco patrem' et 'pudet me vanitatis' pro 'erubesco propter vanitatem' (K: 18, 312)

Hay que advertir que la construcción del verbo antes mencionado se refiere tanto al respeto por una persona honesta como a la vergüenza por una deshonrosa. Así: pudet me patris, con el valor de erubesco patrem ("me avergüenzo ante mi padre"), y pudet me vanitatis con el valor de erubesco propter vanitatem ("me avergënzo de mi vanidad").

[88] 'literas' verisimiliter dicunt appellari, quasi 'legiteras', quod legendi iter praebeant ordine congruo positae (K: 17, 108)

según dicen, se llaman literas -por legiteras-, ya que, si están colocadas en el orden conveniente, facilitan el camino (iter) al lector (legendi).

\section{Orden y expresividad per figuram}

Por último, daremos cuenta aquí de todos aquellos usos que no tendrían fácil acomodo en los apartados precedentes. Aunque los ejemplos en cuestión ofrecen una cierta heterogeneidad, todos ellos pueden en mayor o menor grado ponerse en relación con alguna de las dos especificaciones de referencia que figuran en el título. El número de contextos concernidos no es muy elevado, pues solo asciende a 33 $(4,2 \%)$. Sin embargo, su interés es considerable, puesto que en la mayor parte de los casos nos situamos más allá de los límites en los que la Gramática Tradicional circunscribe la morfosintaxis.

Resulta, en efecto, sorprendente el elevado número de ejemplos que encontramos relativos al orden, en tanto que sucesividad o prevalencia, de los diversos elementos de la lengua en la cadena hablada: 27, lo que supone un porcentaje relativo del $81,8 \%$. Pero tan importante, e incluso más, que la propia cantidad es la gran variedad de hechos de la que dan cuenta los textos aludidos. En [89-100] hemos procurado reflejar tal circunstancia mediante un ejemplo representativo de las variedades más relevantes al respecto.

[89] Literae transmutantur, ut 'Teucer' pro 'Teucre'; sic etiam syllabae, ut 'displicina' pro 'disciplina', nec non etiam dictio, ut 'plebis tribunus' pro 'tribunus plebis', et 'publica res' pro 'res publica'; orationes quoque, ut 'nutrivit filios ac peperit' pro 'peperit ac nutrivit'. Virgilius in II Aeneidos: 
moriamur et in media arma ruamus,

pro 'in media arma ruamus et moriamur' (K: 17, 114)

Se producen transposiciones de letras, como cuando encontramos Teucer en lugar de Teucre; y lo mismo ocurre con las sílabas (displicina' por disciplina), y con palabras: plebis tribunus por tribunus plebis, publica res por res publica; y también con las oraciones: nutrivit filios ac peperit por peperit ac nutrivit. Virgilio en el libro II de Eneida:

moriamur et in media arma ruamus, por in media arma ruamus et moriamur.

[90] Quomodo autem literarum rationem vel scripturae inspectione vel aurium sensu diiudicamus, sic etiam in dictionum ordinatione disceptamus rationem contextus, utrum recta sit an non. nam si incongrua sit, soloecismum faciet, quasi elementis orationis inconcinne coëuntibus, quomodo inconcinnitas literarum vel syllabarum vel eis accidentium in singulis dictionibus facit barbarismum (K: 17, 111)

Si para el estudio de las letras nos hemos basado en el examen de textos y en el oído, para analizar si es correcta o no la ordenación de los términos, partiremos también de su engarce en la frase. En efecto, si aparece alguna incongruencia, se habrá producido un solecismo, por haberse unido elementos de la oración de manera poco coherente, del mismo modo que, cuando se produce esa incongruencia en las letras, en las sílabas o en los accidentes de una palabra, nos hallamos ante un barbarismo.

[91] Multa quoque etiam in aliis partibus invenies similia nec aliter ea discernes nisi ex consequentia ordinationis, id est casus casibus et genera generibus et numeros numeris et personas personis et tempora temporibus, congrue disponendo (K: 17, 200-201)

Y hay también otras muchas coincidencias en otras partes de la oración, que no pueden distinguirse si no es a partir de la construcción, con una disposición apropiada de un caso con otro, un género con otro, un número con otro, una persona con otra.

[92] Sciendum tamen, quod recta ordinatio exigit, ut pronomen vel nomen praeponatur verbo, ut 'ego et tu legimus, Virgilius et Cicero scripserunt', quippe cum substantia et persona ipsius agentis vel patientis, quae per pronomen vel nomen significatur, prior esse debet naturaliter quam ipse actus, qui accidens est substantiae. licet tamen et praepostere ea proferre auctorum usurpatione fretum (K: 17, 164)

Hay que saber, con todo, que la ordenación correcta exige que el pronombre o el nombre vayan antes que el verbo, como ego et tu legimus, Virgilius et 
Cicero scripserunt, ya que la sustancia y la persona, ya sea del agente o del paciente, que es lo consustancial al pronombre o al nombre, deben aparecer naturalmente antes que la propia acción, que es un accidente de la sustancia. Sin embargo, también puede alterarse ese orden poniéndolos después gracias a las licencias de los escritores.

[93] sed auctores frequentissime hyperbatis, id est transitionibus, utuntur, ut:

Aio, te, Aeacida, Romanos vincere posse;

est enim ordo [te Aeacida] 'Romani te possunt vincere', quod et naturaliter passiones secundae sunt actionum et actio in Romanis, passio vero in Pyrrho significatur (K: 18, 234-235)

pero, con frecuencia, los escritores se sirven de hipérbatos, es decir, de alteraciones, como en:

Aio, te, Aeacida, Romanos vincere posse,

donde el orden es: [te Aeacida] Romani te possunt vincere, porque el que recibe la acción normalmente va en segundo lugar, de manera que lo que significa es que la acción la ejercen entonces los romanos, y la sufre Pirro.

[94] nec est mira huiuscemodi ordinatio, cum in eosdem casus resolvitur: est enim 'pudet me tui: pudor me habet tui; taedet me tui: taedium me habet tui; paenitet me tui: paenitentia me habet tui; miseret me tui: miseratio me habet tui' (K: 18, 232-233)

Y no es extraña una ordenación de este tipo, pues se desarrolla mediante casos semejantes, como vemos en pudet me tui ("me da vergüenza de ti"): que equivale a pudor me habet tui ("me domina la vergüenza de ti"); taedet me tui: taedium me habet tui ("me da asco de ti: me domina el asco hacia ti"); paenitet me tui: paenitentia me habet tui ("me disgustas: me domina el disgusto de ti"); miseret me tui: miseratio me habet tui ("me da pena de ti: me domina la pena por ti”).

[95] licet autem pro relativis pronominibus nomina ponere et orationem mutare, ut 'Iuppiter tonat, Iuppiter fulminat'; eae enim orationes singulae per se possunt proferri et invicem converso ordine praepostere dici, cum non ad priorem refertur secunda, quod facit pronomen relativum, quod ad praedictum nomen refertur (K: 17, 142)

Así pues, en todos los pronombres anafóricos hay un único enunciado, que retoma un nombre mencionado con anterioridad. Lógicamente, en lugar de un pronombre anafórico se puede utilizar el nombre y cambiar la oración, como en Iuppiter tonat, Iuppiter fulminat (“Júpiter truena, Júpiter lanza rayos"). Pero estas oraciones pueden aparecer de manera independiente, o con el orden invertido entre ellas, puesto que la segunda no se refiere a la primera, 
que es lo que sí hace el pronombre anafórico al referirse a un nombre que ha aparecido anteriormente.

[96] Aequiperantia etiam quomodo et verba, quae Graeci ioo $\pi \alpha \lambda \tilde{\eta}$, et

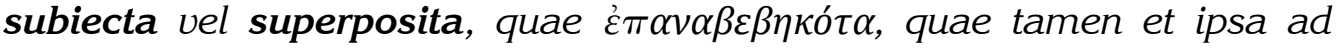
aliquid sunt dicta, de quibus iam diximus, 'subiecta' vero vel 'superposita' dicuntur, quod licet ea et subicere et praeponere, ut 'pater filii' vel 'filio est pater' et 'filius patris' vel 'patri est filius' (K: 18,219)

Son similares las palabras que equiparan, denominadas en griego $i \sigma 0 \pi \alpha \lambda \tilde{\eta}$, también las "subordinadas" o "añadidas a continuación", en griego $\varepsilon \dot{\varepsilon} \alpha \nu \alpha \beta \varepsilon \beta \eta \kappa o ́ \tau \alpha$, de las que ya hemos hablado, y que se añaden también acerca de algo, y aparecen "subordinadas" o "a continuación", aunque se puede poner antes o después del término al que se refieren. Así: pater filii o filio est pater y filius patris o patri est filius.

[97] sic et ex contrario nominativo eius omnes aliorum casus bene adiunguntur, ut 'qui scripsit bucolica Virgilius magnus poëta fuit'; 'qui scripsit Aeneida Virgilii sunt georgica'; 'qui scripsit Aeneida Virgilio gloria contigit'; 'qui scripsit Aeneida Virgilium laudo'; 'qui scripsisti Aeneida, Virgili, vivis memoria'; 'qui scripsit Aeneida Virgilio florent studia'. licet autem et praepostere haec dicere (K: 17, 128)

así también, todos los casos de las demás palabras se relacionan bien con el nominativo de qui, como qui scripsit bucolica Virgilius magnus poëta fuit (“Quien escribió Bucólicas, Virgilio, fue un gran poeta”); qui scripsit Aeneida Virgilii sunt georgica ("Las Geórgicas son de Virgilio, quien escribió La Eneida"); qui scripsit Aeneida Virgilio gloria contigit ("Le llegó la gloria a Virgilio, quien escribió La Eneida"); qui scripsit Aeneida Virgilium laudo ("alabo a Virgilio, quien escribió La Eneida"); qui scripsisti Aeneida, Virgili, vivis memoria ("vives en el recuerdo, Virgilio, que escribiste La Eneida"); qui scripsit Aeneida Virgilio florent studia ("los estudios florecen gracias a Virgilio, que escribió La Eneida"). Y estas mismas expresiones pueden utilizarse también invirtiendo el orden.

[98] Пعрí apud illos et praeponitur et postponitur et diversas habet significationes, quomodo et apud nos 'de' et 'prae' et 'pro' et pleraeque praepositiones (K: 18, 344-345)

Пعрí en griego también se construye antepuesto o pospuesto, con diversos significados, al igual que entre nosotros de, prae, pro y otras muchas preposiciones.

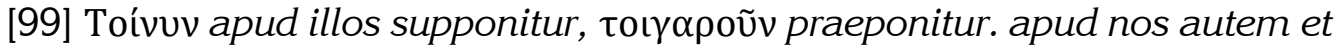
'igitur' et 'ergo' tam praeponuntur quam supponuntur $(\mathrm{K}: 18,369)$ 


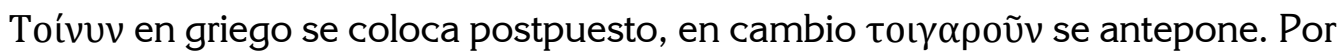
nuestra parte, en latín igitur y ergo ("así pues, luego") tanto se colocan antes como después.

[100] Virgilius in III georgicon: septem subiecta trioni, pro 'septemtrioni subiecta' $(\mathrm{K}: 17,113)$

Virgilio en el libro III de Geórgicas:

septem subiecta trioni, en lugar de septemtrioni subiecta.

Por otro lado, los 4 ejemplos restantes (18,1\% de porcentaje relativo) dan cuenta de hechos que stricto sensu eran calificados en la tratadística antigua como figurae, a las que explícita o implícitamente el propio Prisciano alude, como se puede comprobar en [101-104].

[101] nam si incongrua sit, soloecismum faciet, quasi elementis orationis inconcinne coëuntibus, quomodo inconcinnitas literarum vel syllabarum vel eis accidentium in singulis dictionibus facit barbarismum $(\mathrm{K}: 17,111)$

En efecto, si aparece alguna incongruencia, se habrá producido un solecismo, por haberse unido los elementos de la oración de manera poco coherente, del mismo modo que, cuando se produce esa incongruencia en las letras, en las sílabas o en los accidentes de una palabra, nos hallamos ante un barbarismo.

[102] supervacuum est in re tam manifesta usus auctorum testimonia proferre; illud tamen sciendum, quod per figuram, quam Graeci $\alpha \lambda \lambda$ oьó $\tau \eta \tau \alpha$ vocant, id est variationem, et per $\pi \rho o ́ \lambda \eta \psi \iota v$ vel $\sigma \hat{v} \lambda \lambda \eta \psi \iota v$, id est praeceptionem sive conceptionem (K: 17, 183-184)

No merece la pena ofrecer ejemplos de distintos autores para mostrar un hecho tan evidente, pero hay que saber que, mediante la figura que los griegos denominan $\dot{\alpha} \lambda \lambda$ oเó $\uparrow \eta \tau$, esto es "variación", ya sea por $\pi \varrho o ́ \lambda \eta \psi \iota \nu$ o

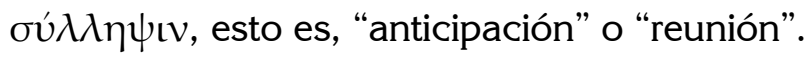

[103] licet tamen variare, ut 'et legisti et lege; et legisti et utinam legas' (K: $17,162)$

Pero también es posible que varíen, como en et legisti et lege ("no sólo leíste, también lee"), et legisti et utinam legas ("no sólo leíste, también ojalá leas"). 
[104] vocativo enim pronomina non egent, qui nec demonstrationem nec relationem, quibus funguntur pronomina, possidet, sed solam conversionem,

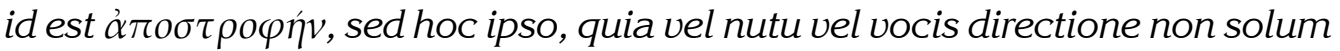
ad eos, quos videmus, sed etiam ad illos, ad quos vox nostra potest pervenire etiam absentes, vocare solemus vel ignorantes propria eorum nomina vel confuse hoc utentes etiam ad multos, ut unus ex eis respondeat, ut ad servos 'tu' dicimus (K: 17, 202)

Así pues, los pronombres necesitan vocativo, que no tiene ni carácter deíctico ni anafórico, que son las funciones pronominales, sino solamente de llamada,

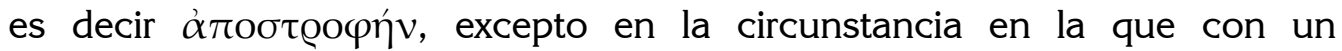
movimiento de cabeza o dirigiendo nuestra voz, no sólo llamamos a aquellos a los que vemos, sino también a aquellos a los que puede llegar nuestra voz, aunque no estén junto a nosotros, o bien cuando ignoramos su nombre propio, o bien cuando, utilizándolo de forma confusa al referirnos a una multitud, para que nos responda uno de ellos, le decimos a unos esclavos "tú".

\section{Algunas consideraciones sobre el método expositivo}

Como ya se ha dicho al inicio del presente artículo, la densidad conceptual y expositiva ${ }^{5}$ de la obra que nos ocupa justifican que Prisciano se sirviera con cierta frecuencia de aclaraciones de tipo metagramatical para informar al lector sobre la disposición del material en relación con una consulta más eficaz y más completa, o bien sobre opiniones personales que completaban y perfilaban mejor el alcance de las consideraciones gramaticales propiamente dichas. Unos breves apuntes nos permitirán hacernos una idea de la importancia e interés de este hecho. Tres son los campos básicos a los que nos vamos a referir en este apartado: a.- disposición del material; b.- acotaciones cuantitativas; c.- valoración cualitativa.

Vayamos a la primera de ellas. En algunos casos Prisciano explicita que de una parte de la información concerniente al asunto que se está tratando se dará cuenta más adelante. Tal circunstancia, aunque no muy frecuente, resulta de gran interés, pues pone en evidencia que el autor tenía un diseño general de la obra o/y que actúa con una estrategia compositiva donde el orden de presentación de los hechos estaba estrechamente ligado al lugar que cada uno de ellos tenía en el plan general. Un ejemplo bastará para entender la relevancia y complejidad este asunto:

[105] Possumus autem et amplioribus rationibus de ordinatione partium demonstrare; sed quia non de ea propositum nobis est, sufficiat hucusque dicere.

Illud etiam primum quaerendum, antequam de constructione singularum orationis partium tractemus, quare interrogativa dictionum in duas partes orationis solas concesserunt (K: 17,121)

Podemos ofrecer aún más razones sobre la ordenación de las partes, pero como no es ese nuestro objetivo, basta con lo ya dicho. 
En primer lugar, antes de tratar de la construcción de las distintas partes de la oración, debemos plantearnos por qué los términos interrogativos han quedado incluidos en dos partes de la oración únicamente.

A veces simplemente se anuncia que el desarrollo de un aspecto particular se deja para más adelante:

[106] Graeci quoque frequenter hoc utuntur, modos verborum pro modi ponentes, de quibus in Atticismis, quibus Romani quoque utuntur, post ostendetur (K: 18, 229).

También en griego con frecuencia observamos este hecho, el que se usen unos modos en lugar de otros, como veremos en los aticismos, que también se usan en latín.

Por otro lado, hay que reseñar que Prisciano también ponía un particular cuidado en recordar que algo había sido tratado ya, en todo o en parte, con anterioridad. Por eso encontramos expresiones del tipo ut paulo ante ostendimus (K: 17, 203), ut saepe diximus (K: 18, 272; 18, 266), quod etiam de participio diximus (K: 17, $120)$, praediximus (K: 17, 174; 17, 181; 18: 272); praedictum (K: 17, 141; 17,142; $17,143 ; 17,175 ; 17,176 ; 17,205)^{6}$.

Que Prisiciano era plenamente consciente de que la presentación del material seguía un orden expositivo lo pone también de manifiesto el hecho de que en ocasiones se haga notar de manera explícita el final de un asunto mediante, por ejemplo, el adverbio postremo (K: 18,217). Por otro lado, no está fuera de lugar señalar que Prisciano también era capaz de ofrecer exposiciones sintéticas y dejar constancia expresa de ello con comentarios del tipo: ut breviter vim eius colligam (K: 18, 247).

Pasamos ahora a las 'acotaciones' que con frecuencia hace Prisciano sobre diferentes aspectos de la lengua. En ocasiones se trata de valoraciones cuantitativas, y otras veces son de tipo cualitativo. Haremos una exposición separada de cada una de ellas, pues entendemos que no carece de interés tal distinción. Veamos, para empezar, los aspectos más relevantes de las valoraciones cuantitativas. La primera circunstancia de la que queremos dejar constancia es que Prisciano parece aplicar los distintos términos cuantificadores a los hablantes en general (nostri, Romani, Graeci, Attici) y a los auctores, ya fueran técnicos (gramáticos) o literarios ${ }^{7}$ E abanico de expresiones que utiliza nuestro gramático para dar cuenta de lo más o menos extendido que estaba un uso lingüístico es verdaderamente digno de tener presente, pues va desde consideraciones imprecisas del tipo solent auctores (K: 17, 192; 18, 22) o invenitur tamen (K: 17, 162; K: 18, 238) hasta las más explícitas y

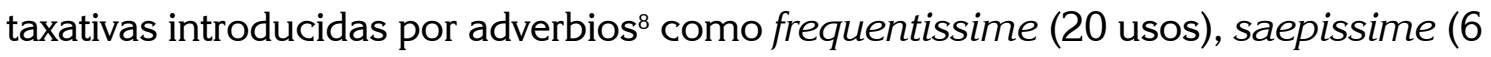
usos) o latissime (1 uso). Entre uno y otro extremo encontramos indicadores de frecuencia del tipo saepe (14 usos), frequenter (48 usos), saepius (4 usos), frequentius (7 usos). 
Por último, pero no menos importante, revisaremos las 'acotaciones cualitativas'. Daremos cuenta en lo que sigue de aquellos comentarios en los que Prisciano emite un juicio valorativo sobre la 'aceptabilidad' de la construcción concernida en cada caso. Hablamos de 'aceptabilidad' en un sentido amplio, porque no se trata sólo de si una construcción es correcta o no, sino que a menudo tiene en cuenta la oportunidad y eficacia con que se hace dicho uso, lo que justifica precisamente que el sistema de evaluación sea también gradual. Veamos, pues, cómo se articula este en sus variables más representativas.

Uno de los modelos utilizados es el que se basa en el esquema que tiene como referencia el término apte. En él encontramos representados los tres niveles que hemos descrito en líneas anteriores a propósito, por ejemplo, de saepe: apte (3 usos), aptius (3 usos), aptissime (9) ${ }^{9}$. Otros casos menos frequentes serían el de proprie (7 usos) y proprius (2 usos), o el de recte (6 usos), rectius (1 uso), rectus-aum (3 usos). Sin embargo, hay términos que no usan las posibilidades de esta fórmula escalar, y se limitan al uso del adverbio (o adjetivo) en el grado positivo. Ello ocurre, por ejemplo, con inconcinne (1 uso), con incongrue (5 usos) e incongruusa-um (2 usos), y con congrue (5 usos) y congruus-a-um (8 usos). Nótese, y ello no lo consideramos mera casualidad, que en este último caso que nos ocupa los usos con adjetivos superan a los usos con adverbios. También es relevante el hecho de que las fórmulas cualitativas superen en variedad a las cuantitativas, de las que hemos dado cuenta un poco más arriba. Así, a las ya aludidas podemos añadir otras como: commode (1 uso), sine dubio (7 usos), figurate (18 usos), minime (6 usos), rationabiliter (4 usos).

Por último, no podemos olvidar que a veces Prisciano hace consideraciones valorativas de índole metagramatical (entendido el concepto lato sensu), como en [107] ${ }^{10}$; nótese que aquí aparece iure, adverbio que no se utiliza en ninguno de los contextos valorativos a los que hemos aludido en líneas anteriores:

[107] Post supra dicta vero omnia coniunctio iure accipitur, cum nullum possit per se significare sensum absque supra positarum dictionum materia (K: 17,121)

Después de todas las partes mencionadas, debe aparecer la conjunción, que no tiene significado alguno por sí misma, si no fuera por la materia de las partes anteriores.

\section{Apostilla final}

Una vez que hemos hecho recuento y análisis de la variedad de usos y recursos con que Prisciano plasma su impronta personal en las Institutiones grammaticae (Priscianus minor), creemos que puede confirmarse la hipótesis de trabajo con que comenzábamos nuestras indagaciones. En efecto, el insigne gramático se muestra tan meticuloso en la exposición de sus teorías gramaticales que precisa servirse de un método expositivo muy elaborado para acometer una tarea tan compleja de un modo eficaz, de suerte que no solo optimice el modo de disponer los materiales 
para evitar tediosas repeticiones, sino que también recurra a mecanismos metadiscursivos para que el lector/usuario de su obra pueda utilizarla de la manera más ágil posible y sacando de ella el máximo provecho.

En lo que hace a los contenidos gramaticales propiamente dichos, el material no se presenta de una forma neutra y despersonalizada, sino que el autor constantemente hace aclaraciones valorativas sobre la mayor o menor bondad de las propuestas que se presentan como posibles. Pero tal vez el mayor interés que para nosotros pueda tener el Priscianus minor radica en el hecho de que dicho tratado es el mejor exponente de los avances que la gramática latina experimentó en la Antigüedad, y sin los cuales no hubiésemos podido ni entender el alcance real de dichos conocimientos técnicos, ni, por otro lado, contextualizar de manera apropiada los refinamientos lingüísticos que los grandes escritores latinos mostraron en sus escritos y el mérito que el gramático Prisciano, en tanto que arbiter elegantiae, les otorgaba. Bien mirada la cuestión, podríamos decir que el análisis detallado que en este trabajo hemos tratado de llevar a efecto ha venido a (de-)mostrar que la obra gramatical de Prisciano en general, y, de forma particular, el Priscianus minor, no hace sino corroborar en cada uno de sus extremos las palabras del rétor de Calahorra, Quintiliano, que citábamos al inicio del mismo: itaque, si antiquum sermonem nostro comparemus, paene iam quidquid loquimur figura est. Tal circunstancia justifica, a su vez, desde el punto de vista metodológico, lo oportuno y necesario que resultaba un análisis pormenorizado y sistemático, como el que aquí hemos intentado realizar, de los diferentes planos y secciones en que puede dividirse la morfosintaxis, por mucho que ello entrañe una exposición compleja y hasta cierto punto prolija.

Con todo, el escrupuloso examen de los detalles nos ha permitido vislumbrar algo que todavía puede resultar de mayor interés, a saber, la 'modernidad', entendida lato sensu, que se adivina en la forma en que aparecen perfiladas con frecuencia las opiniones y conclusiones que Prisciano sustancia y que a menudo no sólo pueden pueden ser consideradas 'sintácticas' en el moderno sentido del término, sino incluso de 'proto-pragmáticas'. Esta última valoración merecería un comentario aclaratorio sobre su verdadero alcance. En efecto, es cosa sabida que detrás de ciertas consideraciones formales que se hacían desde el ámbito de la retórica clásica bien podrían calificarse de pre-pragmáticas, en tanto que apuntaban en la misma dirección que en la actualidad pueden hacerlo tesis pragmalingüísticas propiamente dichas. Sin embargo, cuando afirmamos que por momentos en el Prisciano minor atisbamos indicios de tesis proto-pragmáticas, estamos sugiriendo que si los argumentos que allí se encuentran sólo apuntados en sus rasgos definitorios más elementales se llevasen hasta sus últimas conscuencias, éstas serían de (cuasi-)pleno derecho pragmáticas. De ahí que la, por momentos, modernidad implícita de Prisciano no sea una de las conclusiones menores que nuestro estudio ha pretendido poner en evidencia. 


\section{Bibliografía}

GLÜK, M. (1967). Priscians Partitiones und ihre Stellung in der spätantiken Schule, Hildesheim (Mit einer Beilage: Commentarii in Prisciani Partitiones medio aevocompositi). Olms.

GutiéRrez, M. A. (Dir.) (2013). DECOTGREL (Pmin). Diccionario electrónico concordado de términos gramaticales y retóricos latinos. Cilengua.

GutiÉRREZ, M. A. (1990). L'interprétation des théories de grammairiens latins sur les conjonctions selon le structuralisme fonctionnel. Glotta, 68,105-118.

GUTIÉRREZ, M. A. (1988). La oposición estructural copulativas/disyuntivas en los gramáticos latinos. Veleia, 5, 287-291.

HARTO, M. L. (2015). Prisciano. Sintaxis (Sobre la construcción y el orden de las partes de la oración). Ediciones Clásicas.

KASTER, R. A. (1988). Guardians of Language: The Grammarian and Society in Late Antiquity. University of California Press.

KEIL, H. (1961). Grammatici Latini (I-VIII). Teubner; Olms. (Original publicado en 1855)

Notas

${ }^{1}$ Este trabajo se ha realizado en el marco del Proyecto de Investigación FFI2011-26114, financiado por el MINECO. Debido a la extensión del presente trabajo ha sido preciso dividirlo en dos partes. La primera entrega (I) ha aparecido en el número 41 de la Revista Argos.

${ }^{2}$ En otros lugares del Priscianus maior (por ejemplo, K: 13, 4 y K: 2, 55) encontramos consideraciones de esta misma índole referidas a otras partes del discurso.

${ }^{3}$ Con todo, no queremos decir que 'habitual' suponga, a su vez, generalizado o sistemático. Este asunto solo podría debatirse en profundidad teniendo en cuenta los datos que conciernen a todas las Institutiones grammaticae. Aquí nos limitamos a ofrecer una visión esquemática de una parte del material. Por lo tanto, aunque con ello podamos perfilar los asuntos básicos del problema, ha de tomarse como una primera aproximación, no carente por ello de interés.

${ }^{4}$ Esto sucede en 3 de los 15 ejemplos que, según hemos indicado, tienen como referencia formal una sola palabra.

${ }^{5}$ Como él mismo subraya al inicio del Priscianus minor: necessariam ad auctorum expositionem omnium diligentissime debemus inquirere (K: 17, 108) ("algo que debemos estudiar detallada y oblitagoriamente para la comprensión de cualquier autor").

${ }^{6}$ Recordemos, de pasada, que en el Priscianus minor encontramos el adverbio latius en 7 ocasiones. A veces se emplea para remitirse a un asunto ya tratado (latius diximus, K: 17, 144), a veces para referirse a uno que va a tratar (latius tractabuntur, K: 17, 198). También cabe señalar que el adverbio superius se utiliza en 8 ocasiones para recordar que algo ha 
sido dicho o tratado con anterioridad, y la preposición supra acompañando al verbo dico, ostendo o similares en 25 ocasiones.

7 Sobre el alcance del término auctores véase KASTER (1988: passim). Un problema diferente, y a la vez difícil de dilucidar, es en qué medida él utilizaba cada una de estas fuentes y, en caso de duda, cuál de ellas era tomada como referencia para sancionar un buen (o mal) uso de la lengua. Téngase en cuenta, por otro lado, que Prisciano vivía en Cesarea, donde la lengua mayoritaria era el griego, lo que nos hace sospechar que el peso de la auctoritas de los autores literarios en su caso concreto era superior a la que podía tener en zonas donde de manera generalizada la lengua materna era el latín.

${ }^{8}$ En proporción mucho menor encontramos utilizados para tales fines adjetivos del tipo frequentissimus-a-um (3 usos) o frequens (3 usos).

${ }^{9}$ Al grado superlativo habría que añadir dos usos más que proporciona el adjetivo aptissimus-a-um.

${ }^{10}$ También algunos usos de minime podrían tener esta misma valoración; así, por ejemplo, minime est verum (K: 18, 327), o minime mireris (K: 18, 210). 